\title{
Profilin as a regulator of the membrane-actin cytoskeleton interface in plant cells
}

\section{Tiantian Sun, Shanwei Li and Haiyun Ren*}

Key Laboratory of Cell Proliferation and Regulation Biology of Ministry of Education, College of Life Science, Beijing Normal University, Beijing, China

\section{Edited by:}

Christopher J. Staiger, Purdue

University, USA

\section{Reviewed by:}

Rashid Ali, University of Connecticut, USA

Frantisek Baluska, University of Bonn, Germany

\section{*Correspondence:}

Haiyun Ren, Key Laboratory of Cell Proliferation and Regulation Biology of Ministry of Education, College of Life Science, Beijing Normal University,

No. 19, Xin Jie Kou Wai Street, Beijing 100875, China

e-mail:hren@bnu.edu.cn
Membrane structures and cytoskeleton dynamics are intimately inter-connected in the eukaryotic cell. Recently, the molecular mechanisms operating at this interface have been progressively addressed. Many experiments have revealed that the actin cytoskeleton can interact with membranes through various discrete membrane domains. The actinbinding protein, profilin has been proven to inhibit actin polymerization and to promote F-actin elongation. This is dependent on many factors, such as the profilin/G-actin ratio and the ionic environment of the cell. Additionally, profilin has specific domains that interact with phosphoinositides and poly-L-proline rich proteins; theoretically, this gives profilin the opportunity to interact with membranes, and a large number of experiments have confirmed this possibility. In this article, we summarize recent findings in plant cells, and discuss the evidence of the connections among actin cytoskeleton, profilin and biomembranes through direct or indirect relationships.

\section{Keywords: actin cytoskeleton, profilin, plasma membrane, organelle, vesicle, plants}

\section{INTRODUCTION}

The membrane is a lipid bilayer that functions to divide and separate the cells and organelles. It undergoes many dynamic morphological changes during cellular processes such as endocytosis, exocytosis, vesicular transport, and morphogenesis. Growing evidence has demonstrated that actin cytoskeleton dynamics are involved in these processes. However, the interactions between microfilaments and membranes vary in different cell types and locations. Some cytoskeletal elements may interact with membranes directly. Transmembrane proteins can regulate membrane-cytoskeleton interactions directly or indirectly through adaptor proteins or adaptor complexes. Furthermore, some proteins have domains that can associate with the membrane, and domains that can interact with cytoskeletal components. These are the main types of membrane-cytoskeleton interactions (Doherty and McMahon, 2008). The extracellular matrix (ECM) of animals mainly consists of proteinaceous materials. However, the plant cell wall, which deviates plant cell from spherical shapes, mainly consists of carbohydrates. This implies that there are differences in the intermolecular interactions that occur in membrane-cytoskeleton of animal and plant. In mammals, cytoskeletal proteins that can function as adaptors, such as talin (Heise etal., 1991), vinculin (Geiger etal., 1980), and filamin (Stossel et al., 2001) bind the actin cytoskeleton to membranes; homologs of these proteins are absent from plants (Hussey et al., 2002). There are many plant-specific linker molecules. For example, myosin VIII binds directly or indirectly to plasma membrane-localized callose synthase complexes (Verma and Hong, 2001; Ostergaard etal., 2002) and it also binds to actin filaments in the cytoplasm, which implies that myosin VIII associates plasma membrane with actin filaments in plants. Moreover, a plant-specific Networked (NET) superfamily of actin-binding proteins is found in Arabidopsis. Members of the NET superfamily localize to the actin cytoskeleton and specify different membrane compartments. NET1A is located at the plasma membrane and binds directly to actin filaments through a novel actin-binding domain. The NET superfamily is grouped into four phylogenetic clades, and other members have functions at the tonoplast, nuclear membrane, and pollen tube plasma membrane, which suggest that this superfamily is involved in regulating actin-membrane interactions (Deeks et al., 2012).

A large amount of literature has fostered our current understanding of the membrane, the actin cytoskeleton, and of actinbinding proteins that mediate membrane and actin cytoskeleton components. Profilins are actin-binding proteins, and have the capacity to interact with three classes of ligands. In addition to G-actin, they also associate with poly-L-proline (PLP) which can interact with the binding cleft formed from the $\mathrm{N}$-terminal and C-terminal helices of profilin (Metzler et al., 1994; Mahoney et al., 1999) and phosphoinositides (Gibbon and Staiger, 2000; Jockusch et al., 2007) which offers the possibility that profilin interacts with the membrane. In recent years, much evidence has been verified that profilins can interact with membranes directly or indirectly. In this review, we will summarize recent findings and focus predominantly on the functions of profilins in the direct or indirect relationships among actin cytoskeleton, profilin and membranes in plant cells.

\section{MULTIFUNCTIONAL PROFILINS}

Genomic DNA sequences of putative profilins contain three exons; these may be separated by introns of different sizes (Huang et al., 1996), and are dispersed throughout the genome. Comparing the amino acid sequences of different profilins reveal that profilins have less than $25 \%$ identity across different kingdoms (Pollard and Quirk, 1994), but are highly conserved, with at 
least 70\% identity, across various plant species (Mittermann et al., 1995; Vidali etal., 1995). This is consistent with the analysis of the phylogenetic tree shown in Figure 1. Although the secondary and tertiary structures of all profilins are well conserved (Fedorov et al., 1997; Thorn et al., 1997; Jockusch et al., 2007), the fact that many varieties of profilins isoforms exist in different species, and even in the same organism, may indicate that members of the profilin family have diverse functions. Plant profilins are from multigene families and can be divided into two major groups: the vegetative group, in which profilins exist extensively and are constitutively expressed in all plant tissues; and the reproductive group, where profilins are expressed in reproductive tissues (Kandasamy et al., 2002). The Arabidopsis profilin family includes five highly different isoforms: AtPRF1-AtPRF5; AtPRF1-AtPRF3 belong to the vegetative class, and AtPRF4 and AtPRF5 to the reproductive class (Christensen et al., 1996; Kandasamy et al., 2002). AtPRF1 has much higher affinities for both PLP and G-actin than AtPRF2 (Wang et al., 2009). The tobacco profilin gene, pronp 1 , is prominently expressed in mature pollen, elongating pollen tubes, and the root hairs of developing seedlings. Pronp1 represents a unique profilin as it has activities in two kinds of tip-growing cells, the pollen tubes and root hairs, which rapidly regulate the organization of the actin cytoskeleton (Swoboda et al., 2001). In tomato, LePRO1 was found to be expressed only in pollen grains, and not in other parts of the anther or in other organs using a non-radioactive labeling method (Yu et al., 1998). RcPRO1, a Ricinus communis phloem profilin, is expressed in epidermal, cortex, pith, and xylem tissue. In the sieve-tube exudates, RcPRO1 has 15-fold molar excess to actin, which suggests that actin filament formation is blocked in the assimilate stream (Schobert et al., 2000). In maize, five profilins have been identified (ZmPRO1-ZmPRO5); ZmPRO1-ZmPRO3 are major profilin isoforms of a pollen-abundant class, whereas $\mathrm{ZmPRO} 4$ and ZmPRO5 appear to be members of a predominantly endosperm profilin class. Furthermore, ZmPRO1 inhibits hydrolysis of membrane phosphatidylinositol-4, 5-bisphosphate $\left(\mathrm{PIP}_{2}\right)$ by phospholipase $\mathrm{C}$ more effectively than ZmPRO5. Conversely, ZmPRO5 has higher affinity for PLP and sequesters more monomeric actin to inhibit actin polymerization better than ZmPRO1 (Staiger et al., 1993; Kovar et al., 2000). Currently, there are over 400 profilins from 100 plant species, which are effective at NCBI GenBank database (Pruitt et al., 2007; Jimenez-Lopez et al., 2012). All of the above evidences support that profilins are multifunctional proteins according to their expressions and locations.

\section{PROFILIN IS INVOLVED IN PLASMA MEMBRANE-ACTIN CYTOSKELETON INTERACTIONS}

Binding interactions between the plasma membrane and the actin cytoskeleton define cell functions such as cytoplasmic streaming, cytokinesis, and endocytosis. Profilin is one of the crucial linkers of the membrane-cytoskeleton interaction. The inherent interaction of the actin cytoskeleton with the plasma membrane is through the relationship between actin-binding proteins and $\mathrm{PIP}_{2}$, which itself localizes to the inner side of the plasma membrane (Nebl et al., 2000; Caroni, 2001). PIP 2 can bind to transmembrane adhesion protein, and also interacts with several actin-binding proteins including profilin (Goldschmidt-Clermont et al., 1990; Heiska et al., 1998; Couchman et al., 2002). Immunofluorescence analysis revealed that at the plasma membrane of maize root cells, $\mathrm{PIP}_{2}$ is targeted to discrete domains that resemble profilinenriched domains. $\mathrm{PIP}_{2}$ redistributes and the actin cytoskeleton remodels following treatment with phospholipase $\mathrm{C}$ activator mastoparan (Baluska et al., 2001). Therefore, profilin may be a linker between the plasma membrane and actin cytoskeleton through $\mathrm{PIP}_{2}$. Furthermore, profilins can interact with the proteins that contain PLP stretches of at least eight to ten prolines in continuous or discontinuous sequences (Schluter et al., 1997). In eukaryotes, formins are a group of actin-binding proteins that contain the FH1 domain with different numbers of PLP stretches; they are considered to act as morphological regulation proteins that direct the assembly of unbranched actin filaments (Paul and Pollard, 2009). Profilins or actin/profilin complexes can interact with the PLP stretches of different formins to promote actin filament polymerization (Chang et al., 1997; Pruyne et al., 2002; Kovar et al., 2006; Paul and Pollard, 2009). Additionally, type I formins contain an N-terminal transmembrane domains; this is the region of formin association with the plasma membrane in plants (Cvrckova et al., 2004). For example, in Arabidopsis, formin homology 6 (AtFH6) interacting with profilin locates at the plasma membrane and is uniformly distributed (Favery et al., 2004). Furthermore, AtFH1 and AtFH5 are reported to associate with the cell membrane (Banno and Chua, 2000; Cheung and $\mathrm{Wu}, 2004$; Ingouff et al., 2005). This verifies that plant type I formins are likely to be membranebound, with AtFH8 being the exception, as it is targeted to the nuclear envelope (Xue et al., 2011). The site of the profilin binding FH1 PLP tracks is on the opposite face of the actin binding site of profilin (Schutt et al., 1993), and this explains why profilin can bind PLP and actin simultaneously without mutual influence (Tanaka and Shibata, 1985; Perelroizen et al., 1994). Profilin has an indirect connection and possibly acts as a regulator in the linkage of the plasma membrane and the actin cytoskeleton.

The plant cell is able to defend itself from infection by exogenous fungi. During this process, the cytoskeleton reorganizes and the papilla localizes at penetration sites, this leads to a thick cell wall being formed to prevent pathogen ingress (Schmelzer, 2002). Material is site-directed to arrive at positions around the fungal infection structure beneath the cell wall, and the actin filament and microtubule re-orientate their structures toward the penetration site (Schmelzer, 2002; Takemoto et al., 2003). In cultured parsley cells, undergoing attack from infection with the oomycetous plant pathogen Phytophthora infestans, profilin is expressed and accumulates at the site of infection on the plasma membrane, and the actin cables focus at the penetration site where Rop GTPases also accumulate (Schutz et al., 2006). In addition, in developing microspores and mature pollen of Zea mays, profilin is associated with the plasma membrane (von Witsch et al., 1998). Profilin accumulates in the tip zone near the plasma membrane in root hairs of Arabidopsis (Braun et al., 1999; Baluska et al., 2000). These results suggest that profilins play a role in both signal transduction and linkage between the plasma membrane and actin cytoskeleton 


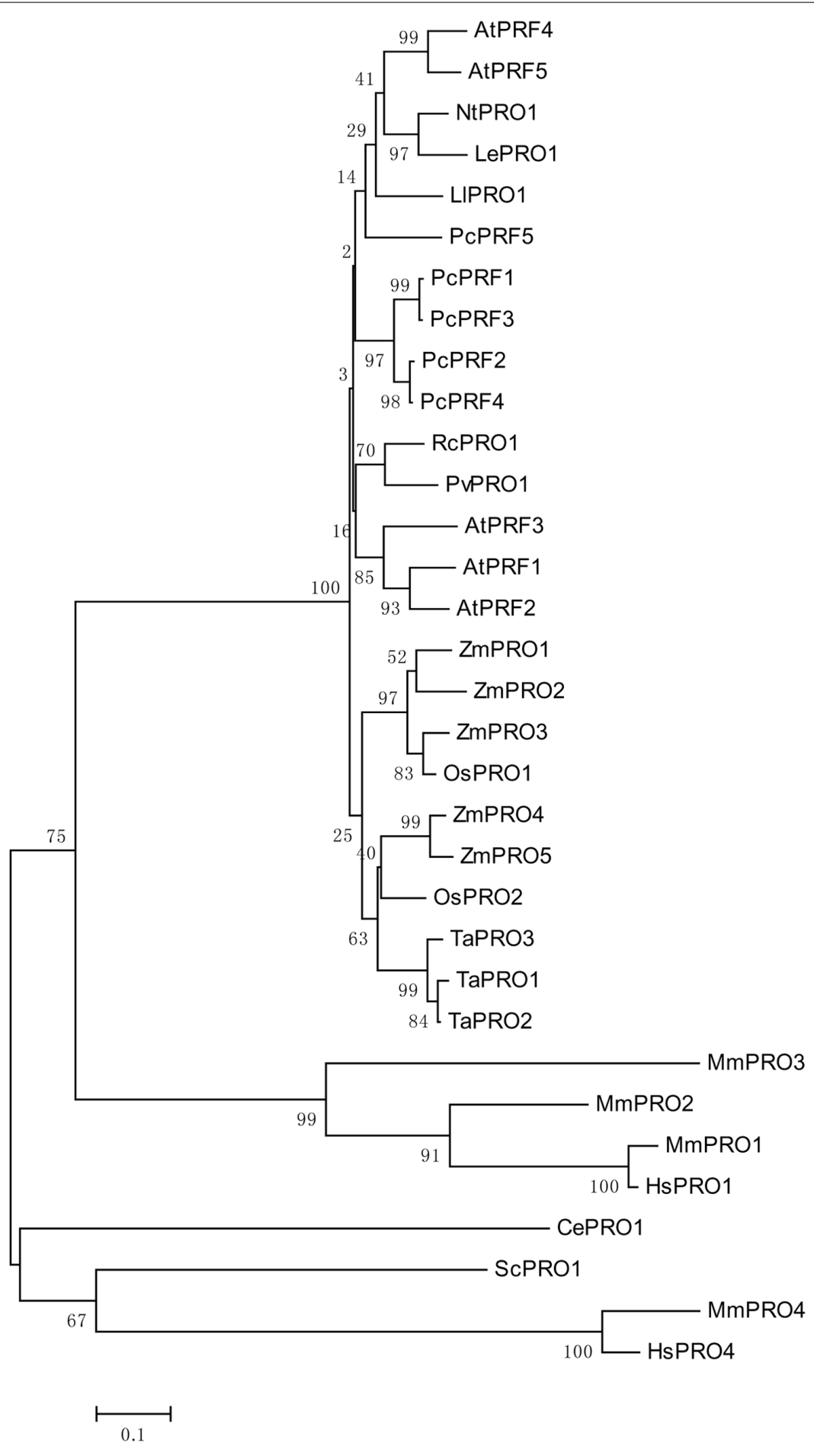

FIGURE 1 | An unrooted phylogenetic tree of profilins. The plant genes are Arabidopsis thaliana AtPRF1-AtPRF5 (AT2G19760, AT4G29350, AT5G56600, AT4G29340, AT2G19770), Petroselinum crispum PcPRF1-PcPRF5 (AY900012-AY900016), Zea mays ZmPRO1-ZmPRO5 (X73279, X73280, X73281, AF032370, AF201459), Oryza sativa OsPRO1-OsPRO2 (LOC_Os10g17680, LOC_Os06g05880), Triticum aestivum TaPRO1-TaPRO3 (X89825-X89827). Nicotiana tabacum NtPRO1 (pronp1 AJ130969), tomato LePRO1 (U50195), Ricinus communis RcPRO1 (AF092547), Phaseolus vulgaris PvPRO1 (CAA57508), Lilium longiflorum LIPRO1 (AF200184).
Selected fungal and metazoan sequences are included: Mus musculus MmPRO1-MmPRO4 (NP_035202, NP_062283, NP_083579, AK013595), Homo sapiens HsPRO1 and HsPRO4 (BC057828, BC029523), Caenorhabditis elegans CePRO1 (PFN-1, NP_493258) Saccharomyces cerevisiae ScPRO1 (PFY1, NP_014765). The percentage of replicate trees in which the associated taxa clustered together in the bootstrap test (1000 replicates) is shown next to the branches (Felsenstein, 1985). The tree is drawn to scale, with branch lengths in the same units as those of the evolutionary distances used to infer the phylogenetic tree. 


\section{PROFILIN IS INVOLVED IN ORGANELLE LOCATION WITH THE ACTIN CYTOSKELETON}

There is much evidence, that in various eukaryotic cells the cytoskeleton is involved in organelle movements. In plant cells, the role of the actin cytoskeleton in organelle movements has been reported for movements of chloroplasts (Kandasamy and Meagher, 1999), the endoplasmic reticulum (ER; Boevink et al., 1998), and the Golgi apparatus (Boevink et al., 1998; Nebenfuhr et al., 1999).

In Arabidopsis, CHUP1 (Chloroplast unusual positioning 1) which is a $112 \mathrm{kDa}$ protein that is closely related with chloroplast movement (Kasahara etal., 2002; Oikawa et al., 2003) is directly targeted to the outer envelope of the chloroplast; this is dependent on its $\mathrm{N}$-terminus domain (Oikawa et al., 2003). In addition to the N-terminus domain, the CHUP1 protein has four other domains, including two leucine-zippers, an actinin-type actin binding domain (Gimona etal., 2002), and a proline-rich motif (PRM) that is similar to PRM1 identified as a profilin binding motif (Holt and Koffer, 2001). A fusion protein which includes GST and the actin binding domain of CHUP1 can bind F-actin in vitro (Oikawa etal., 2003). The in vitro biochemical analyzes revealed that CHUP1 interacts with profilin as a modulator of actin polymerization through the PRM of C-terminal part of CHUP1 (CHUP1-CT). The experiment of CHUP1-CT titrated to a mixture of profilin and actin confirmed that the trimeric complex of actin, profilin, and CHUP1-CT is more stable than the individual binary complex. Though CHUP1 can bind F-actin directly, profilin has been reported to enhance the connection between chloroplasts and actin filaments (Schmidt von Braun and Schleiff, 2008).

Although profilin can bind to formin, the type II formins do not contain the transmembrane domains present in type I formins (Cvrckova et al., 2004). In rice, like other plant type II formins, formin homology 5 (FH5) has a characteristic N-terminal phosphatase tensin (PTEN)-related domain that may interact with membranes (Cvrckova et al., 2004). The experiments of transiently expressing the PTEN-RFP fusion protein in tobacco (Nicotiana tabacum) cells and immunostaining analysis using rice leaf cells revealed that the PTEN-like domain of FH5 is sufficient to confer localization of the protein to the chloroplast surface. This suggests that the PTEN domain of FH5 may be a bridge between chloroplasts and the actin cytoskeleton (Zhang et al., 2011). Furthermore, FH5 was capable of nucleating actin assembly from the actin/profilin complex in vitro biochemical analyzes (Yang etal., 2011; Zhang et al., 2011). Therefore, profilin is indirectly involved in the localization of chloroplast to the actin filaments. In Arabidopsis, observations of living cells in stable transgenic plants revealed that 35S:: GFP-AtPRF1 forms a filamentous network likely associated with actin filaments; this was verified by treatment with latrunculin $\mathrm{A}$, and through a recovery experiment involving the removal of latrunculin A. Whereas, 35S:: GFP-AtPRF2 forms polygonal meshes resembling ER in the same latrunculin A treatment conditions (Wang et al., 2009). Furthermore, in plants, profilins possibly participate in the linkage of the nuclear envelope and the actin cytoskeleton during the interphase of Arabidopsis; this is because AtFH8 locates primarily to the nuclear envelope at this stage (Xue et al., 2011).

\section{PROFILIN IS INVOLVED IN VESICLE TRAFFICKING}

Profilins are known to play an important role in endocytosis and membrane trafficking in lower eukaryotes (Wolven et al., 2000; Pearson etal., 2003). In mammalian cells, profilins may also be involved in membrane trafficking. It has been reported that profilin 1 exists in budding Golgi vesicles, and that dynamin 2 recruitment to the Golgi is dependent on profilin 1 (Dong et al., 2000). Moreover, in mammalian cells, there are multiple phosphoinositide 3-kinases (PI3Ks), and these can be grouped into three main classes. Class I and II PI3Ks can induce receptordependent trafficking processes, such as phagocytosis. Class III PI3Ks, which represent the most ancient form of PI3Ks, and are the only ones conserved in lower eukaryotes, mammals, and plants. Class III PI3Ks mainly regulate receptor-independent trafficking events, such as endocytic membrane traffic (Lindmo and Stenmark, 2006). In animal cells, PI3Ks have been reported to play many different roles in vesicle trafficking, and inhibition of PI3Ks induces the inhibition of clathrin-dependent endocytosis (Martys et al., 1996; Spiro et al., 1996). In plant cells, Class III PI3K protein complexes may have a regulatory function during vesicle trafficking (Matsuoka et al., 1995; Kim et al., 2001; Jung et al., 2002). In Phaseolus vulgaris, in addition to the $\mathrm{N}$ - and C-terminal PLP-binding domain, profilin has a domain around Tyr72; this can recognize and bind PLP and PI3K (AparicioFabre etal., 2006). Profilin can bind directly to Class III PI3Ks in a manner reliant upon the tyrosine phosphorylation status of the PLP domain in profilin. This interaction between profilin and Class III PI3Ks suggests that profilin may participate in membrane trafficking, and may act as a linker between the endocytic pathway and the actin reorganization dynamics (Aparicio-Fabre et al., 2006).

With advances in biotechnology, diverse pharmaceutical drugs have been used to study the interaction between vesicular trafficking and cytoskeleton. Brefeldin A (BFA) is a drug that inhibits the recycling of vesicular trafficking, and disrupts secretion in yeast, mammalian, and plant cells (Vogel et al., 1993; Samaj et al., 2004; Citterio et al., 2008; Robinson et al., 2008). In Arabidopsis roots, BFA-compartments can be formed due to the accumulation of trans-Golgi network (TGN) secretory and recycling vesicles, which gather together following BFA treatment (Geldner et al., 2003). During this process, profilin 2 is up-regulated and accumulates in the BFA-compartments, which then interacts with the actin to remodel the actin cytoskeleton. This study suggested that profilin 2 may bridge vesicular trafficking to the actin cytoskeleton in a BFA-dependent manner (Takac et al., 2011). Table 1 lists the profilins cited in the present article and emphasizes some of their cellular functions. Therefore, the recently investigated interactions between membranes and the actin cytoskeleton have revealed profilins to be of particular interest, this is because they may act as linkers and regulate communication and cooperation between the two cellular members in plants. Currently available studies suggest that diverse interaction mechanisms are required to satisfy the different structural and dynamic requirements of particular systems. Future 
Table 1 | Profilin and its cellular functions in plant cells.

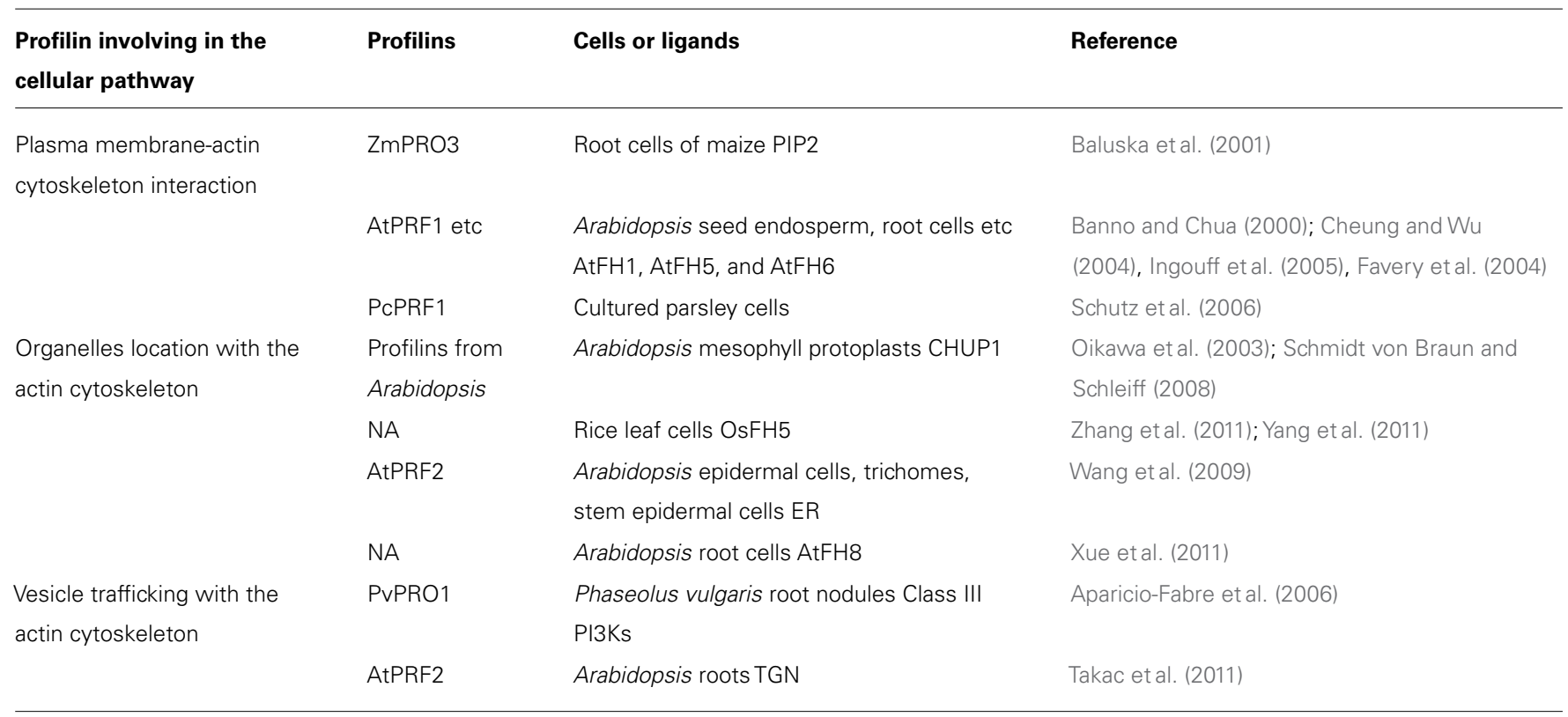

NA, not available.

research is required to unravel how membrane-actin cytoskeleton interactions are regulated through profilins and their different ligands.

\section{ACKNOWLEDGMENTS}

This work was supported by grants from the National Natural Science Foundation of China (31130005) and the National Basic Research Program of China (2013CB126902) to Haiyun Ren.

\section{REFERENCES}

Aparicio-Fabre, R., Guillen, G., Estrada, G., Olivares-Grajales, J., Gurrola, G., and Sanchez, F. (2006). Profilin tyrosine phosphorylation in poly-L-proline-binding regions inhibits binding to phosphoinositide 3-kinase in Phaseolus vulgaris. Plant J. 47, 491-500. doi: 10.1111/j.1365-313X.2006.02787.x

Baluska, F., Salaj, J., Mathur, J., Braun, M., Jasper, F., Samaj, J., et al. (2000). Root hair formation: F-actin-dependent tip growth is initiated by local assembly of profilin-supported F-actin meshworks accumulated within expansin-enriched bulges. Dev. Biol. 227, 618-632. doi: 10.1006/dbio.2000.9908

Baluska, F., von Witsch, M., Peters, M., Hlavacka, A., and Volkmann, D. (2001). Mastoparan alters subcellular distribution of profilin and remodels F-actin cytoskeleton in cells of maize root apices. Plant Cell Physiol. 42, 912-922. doi: $10.1093 /$ pcp/pce116

Banno, H., and Chua, N. H. (2000). Characterization of the arabidopsis formin-like protein AFH1 and its interacting protein. Plant Cell Physiol. 41, 617-626. doi: 10.1093/pcp/41.5.617

Boevink, P., Oparka, K., Santa Cruz, S., Martin, B., Betteridge, A., and Hawes, C. (1998). Stacks on tracks: the plant Golgi apparatus traffics on an actin/ER network. Plant J. 15, 441-447. doi: 10.1046/j.1365-313X.1998. 00208.x

Braun, M., Baluska, F., von Witsch, M., and Menzel, D. (1999). Redistribution of actin, profilin and phosphatidylinositol-4, 5-bisphosphate in growing and maturing root hairs. Planta 209, 435-443. doi: 10.1007/s0042500 50746

Caroni, P. (2001). Actin cytoskeleton regulation through modulation of $\mathrm{PI}(4,5) \mathrm{P}(2)$ rafts. EMBO J. 20, 4332-4336. doi: 10.1093/emboj/20.16.4332

Chang, F., Drubin, D., and Nurse, P. (1997). cdc12p, a protein required for cytokinesis in fission yeast, is a component of the cell division ring and interacts with profilin. J. Cell Biol. 137, 169-182. doi: 10.1083/jcb.137.1.169
Cheung, A. Y., and Wu, H. M. (2004). Overexpression of an Arabidopsis formin stimulates supernumerary actin cable formation from pollen tube cell membrane. Plant Cell 16, 257-269. doi: 10.1105/tpc.016550

Christensen, H. E., Ramachandran, S., Tan, C. T., Surana, U., Dong, C. H., and Chua, N. H. (1996). Arabidopsis profilins are functionally similar to yeast profilins: identification of a vascular bundle-specific profilin and a pollen-specific profilin. Plant J. 10, 269-279. doi: 10.1046/j.1365-313X.1996.10020269.x

Citterio, C., Vichi, A., Pacheco-Rodriguez, G., Aponte, A. M., Moss, J., and Vaughan, M. (2008). Unfolded protein response and cell death after depletion of brefeldin A-inhibited guanine nucleotide-exchange protein GBF1. Proc. Natl. Acad. Sci. U.S.A. 105, 2877-2882. doi: 10.1073/pnas.0712224105

Couchman, J. R., Vogt, S., Lim, S. T., Lim, Y., Oh, E. S., Prestwich, G. D., et al. (2002). Regulation of inositol phospholipid binding and signaling through syndecan-4. J. Biol. Chem. 277, 49296-49303. doi: 10.1074/jbc.M209679200

Cvrckova, F., Novotny, M., Pickova, D., and Zarsky, V. (2004). Formin homology 2 domains occur in multiple contexts in angiosperms. BMC Genomics 5:44. doi: 10.1186/1471-2164-5-44

Deeks, M. J., Calcutt, J. R., Ingle, E. K., Hawkins, T. J., Chapman, S., Richardson, A. C., et al. (2012). A superfamily of actin-binding proteins at the actin-membrane nexus of higher plants. Curr. Biol. 22, 1595-1600. doi: 10.1016/j.cub.2012. 06.041

Doherty, G. J., and McMahon, H. T. (2008). Mediation, modulation, and consequences of membrane-cytoskeleton interactions. Annu. Rev. Biophys. 37, 65-95. doi: 10.1146/annurev.biophys.37.032807.125912

Dong, J., Radau, B., Otto, A., Muller, E., Lindschau, C., and Westermann, P. (2000). Profilin I attached to the Golgi is required for the formation of constitutive transport vesicles at the trans-Golgi network. Biochim. Biophys. Acta. 1497, 253-260. doi: 10.1016/S0167-4889(00)00056-2

Favery, B., Chelysheva, L. A., Lebris, M., Jammes, F., Marmagne, A., De AlmeidaEngler, J., et al. (2004). Arabidopsis formin AtFH6 is a plasma membraneassociated protein upregulated in giant cells induced by parasitic nematodes. Plant Cell 16, 2529-2540. doi: 10.1105/tpc.104.024372

Fedorov, A. A., Ball, T., Mahoney, N. M., Valenta, R., and Almo, S. C. (1997). The molecular basis for allergen cross-reactivity: crystal structure and IgE-epitope mapping of birch pollen profilin. Structure 5, 33-45. doi: 10.1016/S0969-2126(97)00164-0

Felsenstein, J. (1985). Confidence limits on phylogenies: An approach using the bootstrap. Evolution 39, 783-791. doi: 10.2307/2408678

Geiger, B., Tokuyasu, K. T., Dutton, A. H., and Singer, S. J. (1980). Vinculin, an intracellular protein localized at specialized sites where microfilament bundles 
terminate at cell membranes. Proc. Natl. Acad. Sci. U.S.A. 77, 4127-4131. doi: 10.1073/pnas.77.7.4127

Geldner, N., Anders, N., Wolters, H., Keicher, J., Kornberger, W., Muller, P., et al. (2003). The Arabidopsis GNOM ARF-GEF mediates endosomal recycling, auxin transport, and auxin-dependent plant growth. Cell 112, 219-230. doi: 10.1016/S0092-8674(03)00003-5

Gibbon, B. C., and Staiger, C. J. (2000). "Profilin," in Actin: a Dynamic Framework for Multiple Plant Cell Functions, eds C. J. Staiger, F. Baluska, D. Volkmann, and P. Barlow (Dordrecht, The Netherlands: Kluwer Academic Publishers), 45-65.

Gimona, M., Djinovic-Carugo, K., Kranewitter, W. J., and Winder, S. J. (2002). Functional plasticity of CH domains. FEBS Lett. 513, 98-106. doi: 10.1016/S00145793(01)03240-9

Goldschmidt-Clermont, P. J., Machesky, L. M., Baldassare, J. J., and Pollard, T. D. (1990). The actin-binding protein profilin binds to PIP2 and inhibits its hydrolysis by phospholipase C. Science 247, 1575-1578. doi: 10.1126/science. 2157283

Heise, H., Bayerl, T., Isenberg, G., and Sackmann, E. (1991). Human platelet P-235, a talin-like actin binding protein, binds selectively to mixed lipid bilayers. Biochim. Biophys. Acta. 1061, 121-131. doi: 10.1016/0005-2736(91)90276-E

Heiska, L., Alfthan, K., Gronholm, M., Vilja, P., Vaheri, A., and Carpen, O. (1998). Association of ezrin with intercellular adhesion molecule-1 and -2 (ICAM-1 and ICAM-2). Regulation by phosphatidylinositol 4, 5-bisphosphate. J. Biol. Chem. 273, 21893-21900. doi: 10.1074/jbc.273.34.21893

Holt, M. R., and Koffer, A. (2001). Cell motility: proline-rich proteins promote protrusions. Trends Cell Biol. 11, 38-46. doi: 10.1016/S0962-8924(00)01876-6

Huang, S., McDowell, J. M., Weise, M. J., and Meagher, R. B. (1996). The Arabidopsis profilin gene family. Evidence for an ancient split between constitutive and pollenspecific profilin genes. Plant Physiol. 111, 115-126. doi: 10.1104/pp.111.1.115

Hussey, P. J., Allwood, E. G., and Smertenko, A. P. (2002). Actin-binding proteins in the Arabidopsis genome database: properties of functionally distinct plant actin-depolymerizing factors/cofilins. Philos. Trans. R. Soc. Lond. B Biol. Sci. 357, 791-798. doi: 10.1098/rstb.2002.1086

Ingouff, M., Fitz Gerald, J. N., Guerin, C., Robert, H., Sorensen, M. B., Van Damme, D., et al. (2005). Plant formin AtFH5 is an evolutionarily conserved actin nucleator involved in cytokinesis. Nat. Cell Biol. 7, 374-380. doi: 10.1038/ncb1238

Jimenez-Lopez, J. C., Morales, S., Castro, A. J., Volkmann, D., RodriguezGarcia, M. I., and Alche, J. D. (2012). Characterization of profilin polymorphism in pollen with a focus on multifunctionality. PLOS ONE 7:e30878. doi: 10.1371/journal.pone.0030878

Jockusch, B. M., Murk, K., and Rothkegel, M. (2007). The profile of profilins. Rev. Physiol. Biochem. Pharmacol. 159, 131-149.

Jung, J. Y., Kim, Y. W., Kwak, J. M., Hwang, J. U., Young, J., Schroeder, J. I., et al. (2002). Phosphatidylinositol 3- and 4-phosphate are required for normal stomatal movements. Plant Cell 14, 2399-2412. doi: 10.1105/tpc.004143

Kandasamy, M. K., McKinney, E. C., and Meagher, R. B. (2002). Plant profilin isovariants are distinctly regulated in vegetative and reproductive tissues. Cell Motil. Cytoskeleton 52, 22-32. doi: 10.1002/cm.10029

Kandasamy, M. K., and Meagher, R. B. (1999). Actin-organelle interaction: association with chloroplast in arabidopsis leaf mesophyll cells. Cell Motil. Cytoskeleton 44, 110-118. doi: 10.1002/(SICI)1097-0169(199910)44:2<110::AID$\mathrm{CM} 3>3.0 . \mathrm{CO} ; 2-\mathrm{O}$

Kasahara, M., Kagawa, T., Oikawa, K., Suetsugu, N., Miyao, M., and Wada, M. (2002). Chloroplast avoidance movement reduces photodamage in plants. Nature 420, 829-832. doi: 10.1038/nature01213

Kim, D. H., Eu, Y. J., Yoo, C. M., Kim, Y. W., Pih, K. T., Jin, J. B., et al. (2001). Trafficking of phosphatidylinositol 3-phosphate from the trans-Golgi network to the lumen of the central vacuole in plant cells. Plant Cell 13, 287-301.

Kovar, D. R., Drobak, B. K., and Staiger, C. J. (2000). Maize profilin isoforms are functionally distinct. Plant Cell 12, 583-598.

Kovar, D. R., Harris, E. S., Mahaffy, R., Higgs, H. N., and Pollard, T. D. (2006). Control of the assembly of ATP- and ADP-actin by formins and profilin. Cell 124, 423-435. doi: 10.1016/j.cell.2005.11.038

Lindmo, K., and Stenmark, H. (2006). Regulation of membrane traffic by phosphoinositide 3-kinases. J. Cell Sci. 119, 605-614. doi: 10.1242/jcs.02855

Mahoney, N. M., Rozwarski, D. A., Fedorov, E., Fedorov, A. A., and Almo, S. C. (1999). Profilin binds proline-rich ligands in two distinct amide backbone orientations. Nat. Struct. Biol. 6, 666-671. doi: 10.1038/ 10722
Martys, J. L., Wjasow, C., Gangi, D. M., Kielian, M. C., McGraw, T. E., and Backer, J. M. (1996). Wortmannin-sensitive trafficking pathways in Chinese hamster ovary cells. Differential effects on endocytosis and lysosomal sorting. J. Biol. Chem. 271, 10953-10962. doi: 10.1074/jbc.271.18.10953

Matsuoka, K., Bassham, D. C., Raikhel, N. V., and Nakamura, K. (1995). Different sensitivity to wortmannin of two vacuolar sorting signals indicates the presence of distinct sorting machineries in tobacco cells. J. Cell Biol. 130, 1307-1318. doi: 10.1083/jcb.130.6.1307

Metzler, W. J., Bell, A. J., Ernst, E., Lavoie, T. B., and Mueller, L. (1994). Identification of the poly-L-proline-binding site on human profilin. J. Biol. Chem. 269, 46204625 .

Mittermann, I., Swoboda, I., Pierson, E., Eller, N., Kraft, D., Valenta, R., et al. (1995). Molecular cloning and characterization of profilin from tobacco (Nicotiana tabacum): increased profilin expression during pollen maturation. Plant Mol. Biol. 27, 137-146. doi: 10.1007/BF00019185

Nebenfuhr, A., Gallagher, L. A., Dunahay, T. G., Frohlick, J. A., Mazurkiewicz, A. M., Meehl, J. B., et al. (1999). Stop-and-go movements of plant Golgi stacks are mediated by the acto-myosin system. Plant Physiol. 121, 1127-1142. doi: 10.1104/pp.121.4.1127

Nebl, T., Oh, S. W., and Luna, E. J. (2000). Membrane cytoskeleton: PIP(2) pulls the strings. Curr. Biol. 10, R351-R354. doi: 10.1016/S0960-9822(00)00465-6

Oikawa, K., Kasahara, M., Kiyosue, T., Kagawa, T., Suetsugu, N., Takahashi, F., etal. (2003). Chloroplast unusual positioningl is essential for proper chloroplast positioning. Plant Cell 15, 2805-2815. doi: 10.1105/tpc. 016428

Ostergaard, L., Petersen, M., Mattsson, O., and Mundy, J. (2002). An Arabidopsis callose synthase. Plant Mol. Biol. 49, 559-566. doi: 10.1023/A:1015558231400

Paul, A. S., and Pollard, T. D. (2009). Review of the mechanism of processive actin filament elongation by formins. Cell Motil. Cytoskeleton 66, 606-617. doi: $10.1002 / \mathrm{cm} .20379$

Pearson, A. M., Baksa, K., Ramet, M., Protas, M., McKee, M., Brown, D., et al. (2003). Identification of cytoskeletal regulatory proteins required for efficient phagocytosis in Drosophila. Microbes Infect. 5, 815-824. doi: 10.1016/S12864579(03)00157-6

Perelroizen, I., Marchand, J. B., Blanchoin, L., Didry, D., and Carlier, M. F. (1994). Interaction of profilin with G-actin and poly(L-proline). Biochemistry 33, 84728478. doi: 10.1021/bi00194a011

Pollard, T. D., and Quirk, S. (1994). Profilins, ancient actin binding proteins with highly divergent primary structures. Soc. Gen. Physiol. Ser. 49, 117-128.

Pruitt, K. D., Tatusova, T., and Maglott, D. R. (2007). NCBI reference sequences (RefSeq): a curated non-redundant sequence database of genomes, transcripts and proteins. Nucleic Acids Res. 35, D61-D65. doi: 10.1093/nar/gkl842

Pruyne, D., Evangelista, M., Yang, C., Bi, E., Zigmond, S., Bretscher, A., et al. (2002). Role of formins in actin assembly: nucleation and barbed-end association. Science 297, 612-615. doi: 10.1126/science.1072309

Robinson, D. G., Langhans, M., Saint-Jore-Dupas, C., and Hawes, C. (2008). BFA effects are tissue and not just plant specific. Trends Plant Sci. 13, 405-408. doi: 10.1016/j.tplants.2008.05.010

Samaj, J., Baluska, F., Voigt, B., Schlicht, M., Volkmann, D., and Menzel, D. (2004). Endocytosis, actin cytoskeleton, and signaling. Plant Physiol. 135, 1150-1161. doi: 10.1104/pp.104.040683

Schluter, K., Jockusch, B. M., and Rothkegel, M. (1997). Profilins as regulators of actin dynamics. Biochim. Biophys. Acta 1359, 97-109. doi: 10.1016/S01674889(97)00100-6

Schmelzer, E. (2002). Cell polarization, a crucial process in fungal defence. Trends Plant Sci. 7, 411-415. doi: 10.1016/S1360-1385(02)02307-5

Schmidt von Braun, S., and Schleiff, E. (2008). The chloroplast outer membrane protein CHUP1 interacts with actin and profilin. Planta 227, 1151-1159. doi: 10.1007/s00425-007-0688-7

Schobert, C., Gottschalk, M., Kovar, D. R., Staiger, C. J., Yoo, B. C., and Lucas, W. J. (2000). Characterization of Ricinus communis phloem profilin, RcPRO1. Plant Mol. Biol. 42, 719-730. doi: 10.1023/A:1006391508429

Schutt, C. E., Myslik, J. C., Rozycki, M. D., Goonesekere, N. C., and Lindberg, U. (1993). The structure of crystalline profilin-beta-actin. Nature 365, 810-816. doi: $10.1038 / 365810 \mathrm{a} 0$

Schutz, I., Gus-Mayer, S., and Schmelzer, E. (2006). Profilin and Rop GTPases are localized at infection sites of plant cells. Protoplasma 227, 229-235. doi: 10.1007/s00709-005-0151-1 
Spiro, D. J., Boll, W., Kirchhausen, T., and Wessling-Resnick, M. (1996). Wortmannin alters the transferrin receptor endocytic pathway in vivo and in vitro. Mol. Biol. Cell 7, 355-367. doi: 10.1091/mbc.7.3.355

Staiger, C. J., Goodbody, K. C., Hussey, P. J., Valenta, R., Drobak, B. K., and Lloyd, C. W. (1993). The profilin multigene family of maize: differential expression of three isoforms. Plant J. 4, 631-641. doi: 10.1046/j.1365-313X.1993.04040631.x

Stossel, T. P., Condeelis, J., Cooley, L., Hartwig, J. H., Noegel, A., Schleicher, M., et al. (2001). Filamins as integrators of cell mechanics and signalling. Nat. Rev. Mol. Cell Biol. 2, 138-145. doi: 10.1038/35052082

Swoboda, I., Bhalla, P. L., Xu, H., Zhang, Y., Mittermann, I., Valenta, R., et al. (2001). Identification of pronp1, a tobacco profilin gene activated in tip-growing cells. Plant Mol. Biol. 46, 531-538. doi: 10.1023/A:1010641229366

Takac, T., Pechan, T., Richter, H., Muller, J., Eck, C., Bohm, N., et al. (2011). Proteomics on brefeldin A-treated Arabidopsis roots reveals profilin 2 as a new protein involved in the cross-talk between vesicular trafficking and the actin cytoskeleton. J. Proteome Res. 10, 488-501. doi: 10.1021/pr100690f

Takemoto, D., Jones, D. A., and Hardham, A. R. (2003). GFP-tagging of cell components reveals the dynamics of subcellular re-organization in response to infection of Arabidopsis by oomycete pathogens. Plant J. 33, 775-792. doi: 10.1046/j.1365-313X.2003.01673.x

Tanaka, M., and Shibata, H. (1985). Poly (L-proline)-binding proteins from chick embryos are a profilin and profilactin. Eur. J. Biochem. 151, 291-297. doi: 10.1111/j.1432-1033.1985.tb09099.x

Thorn, K. S., Christensen, H. E., Shigeta, R., Huddler, D., Shalaby, L., Lindberg, U., et al. (1997). The crystal structure of a major allergen from plants. Structure 5, 19-32. doi: 10.1016/S0969-2126(97)00163-9

Verma, D. P., and Hong, Z. (2001). Plant callose synthase complexes. Plant Mol. Biol. 47, 693-701. doi: 10.1023/A:1013679111111

Vidali, L., Perez, H. E., Valdes Lopez, V., Noguez, R., Zamudio, F., and Sanchez, F. (1995). Purification, characterization, and cDNA cloning of profilin from Phaseolus vulgaris. Plant Physiol. 108, 115-123. doi: 10.1104/pp.108.1.115

Vogel, J. P., Lee, J. N., Kirsch, D. R., Rose, M. D., and Sztul, E. S. (1993). Brefeldin A causes a defect in secretion in Saccharomyces cerevisiae. J. Biol. Chem. 268, 3040-3043.

von Witsch, M., Baluska, F., Staiger, C. J., and Volkmann, D. (1998). Profilin is associated with the plasma membrane in microspores and pollen. Eur. J. Cell Biol. 77, 303-312. doi: 10.1016/S0171-9335(98)80089-7
Wang, F., Jing, Y., Wang, Z., Mao, T., Samaj, J., Yuan, M., et al. (2009). Arabidopsis profilin isoforms, PRF1 and PRF2 show distinctive binding activities and subcellular distributions. J. Integr. Plant Biol. 51, 113-121. doi: 10.1111/j.1744-7909.2008.00781.x

Wolven, A. K., Belmont, L. D., Mahoney, N. M., Almo, S. C., and Drubin, D. G. (2000). In vivo importance of actin nucleotide exchange catalyzed by profilin. $J$. Cell Biol. 150, 895-904. doi: 10.1083/jcb.150.4.895

Xue, X. H., Guo, C. Q., Du, F., Lu, Q. L., Zhang, C. M., and Ren, H. Y. (2011). AtFH8 is involved in root development under effect of low-dose latrunculin B in dividing cells. Mol. Plant 4, 264-278. doi: 10.1093/mp/ssq085

Yang, W., Ren, S., Zhang, X., Gao, M., Ye, S., Qi, Y., et al. (2011). BENT UPPERMOST INTERNODE1 encodes the class II formin FH5 crucial for actin organization and rice development. Plant Cell 23, 661-680. doi: 10.1105/tpc.110.081802

Yu, L. X., Nasrallah, J., Valenta, R., and Parthasarathy, M. V. (1998). Molecular cloning and mRNA localization of tomato pollen profilin. Plant Mol. Bio. 36, 699-707. doi: 10.1023/A:1005971327353

Zhang, Z., Zhang, Y., Tan, H., Wang, Y., Li, G., Liang, W., et al. (2011). RICE MORPHOLOGY DETERMINANT encodes the type II formin FH5 and regulates rice morphogenesis. Plant Cell 23, 681-700. doi: 10.1105/tpc.110.081349

Conflict of Interest Statement: The authors declare that the research was conducted in the absence of any commercial or financial relationships that could be construed as a potential conflict of interest.

Received: 29 October 2013; paper pending published: 15 November 2013; accepted: 30 November 2013; published online: 19 December 2013.

Citation: Sun T, Li S and Ren H (2013) Profilin as a regulator of the membrane-actin cytoskeleton interface in plant cells. Front. Plant Sci. 4:512. doi: 10.3389/fpls.2013.00512

This article was submitted to Plant Traffic and Transport, a section of the journal Frontiers in Plant Science.

Copyright (c) 2013 Sun, Li and Ren. This is an open-access article distributed under the terms of the Creative Commons Attribution License (CC BY). The use, distribution or reproduction in other forums is permitted, provided the original author(s) or licensor are credited and that the original publication in this journal is cited, in accordance with accepted academic practice. No use, distribution or reproduction is permitted which does not comply with these terms. 